\title{
Marginados, pero no marginales. Negros, mulatos y sus disputas por la autonomía en Chocó, Colombia (1903-1947)*
}

\section{Resumen}

Chocó se caracterizó por ser un territorio con bajos niveles de autonomía política, económica y administrativa. Al ser intendencia y no departamento, electoralmente dependía de Antioquia, jurídicamente del Cauca y administrativamente de Bogotá. En este artículo analizamos los roles de líderes afrodescendientes en la consecución de mayores niveles de autonomía para el Chocó en la primera mitad del siglo XX. Sugerimos que el estatus de intendencia no solo se le asignó por lo que significó la separación de Panamá de Colombia, sino además por las representaciones raciales despectivas que pesaban sobre este territorio y sus habitantes. Funcionarios nacionales, viajeros y miembros de la élite política e intelectual de Colombia insistían en que Chocó era un territorio habitado por salvajes que necesitaba de una suerte de tutelaje de parte del gobierno nacional. Concluimos que sus habitantes negros, lejos de sentirse marginales, adelantaron acciones que fueron definitivos en la consecución del estatus de departamento para este territorio.

\section{Palabras clave:}

Tesauros: autonomía, afrodescendientes, raza.

Autor: Colombia, Chocó.

Referencia bibliográfica para citar este artículo: Rhenals Doria, Ana Milena y Flórez Bolívar, Francisco Javier. "Marginados, pero no marginales. Negros, mulatos y sus disputas por la autonomía en Chocó, Colombia (1903-1947)". Anuario de Historia Regional y de las Fronteras, 24.2 (2019): 125-149.

Fecha de recepción: 27/02/2019

Fecha de aceptación: 03/04/2019

Ana Milena Rhenals Doria: Doctora en historia de América Latina de la Universidad Pablo de Olavide, Sevilla - España (2013). Historiadora de la Universidad de Cartagena, Colombia (2004). Profesora de la Escuela de Historia de la Universidad Industrial de Santander, Colombia. Código ORCID: 00000003-0341-9635. Correo electrónico: mrhenals@uis.edu.co.

Francisco Javier Flórez Bolívar: Doctor en Historia de la Universidad de Pittsburgh, Estados Unidos. Magíster en Historia en la Universidad de Pittsburgh, Estados Unidos. Historiador de la Universidad de Cartagena, Colombia. Miembro del grupo de investigación Historia Económica, Política y Social del Programa de Historia de la Universidad de Cartagena, Colombia, donde labora como docente y dirige la revista El Taller de la Historia. Código ORCID: 0000-0002-9095-7433. Correo electrónico: fflorezb1@unicartagena.edu.co.

\footnotetext{
* Este artículo se basa en los resultados de la investigación Forjando la inclusión: negros y mulatos y las luchas por la igualdad en Colombia, 1880 y 1947 (Francisco Javier Flórez Bolívar); y en el contenido de la ponencia "Cerrar las puertas a los asiáticos": inmigración, salud pública y controles migratorios en Colombia, 1880-1930, presentada por Ana Milena Rhenals Doria en el 25th International Congress of History of Science and Technolgy (Río de Janeiro, 2017). La citada ponencia fue elaborada a partir de la investigación doctoral "Del ideal europeo a la realidad árabe: inmigrantes sirio-libaneses en el circuito comercial de la Provincia del Sinú, el Atrato y Cartagena, 1880-1930”.
} 


\title{
Marginalized, but not Marginals: Blacks and Mulattos and their Disputes for the Territorial Autonomy in Chocó, Colombia (1903-1947)
}

\begin{abstract}
Chocó, due to the status of intendancy that maintained until 1947, was a territory with low levels of political, economic and administrative autonomy. Being an intendancy and not a department, it made Chocó electorally dependent on Antioquia, legally on Cauca and administratively on Bogota. In this article, we study the role that leaders of Afro-descendant origin played in achieving greater levels of territorial autonomy for Chocó during the first half of the 20th century. We suggest that the status of Intendancy, reserved to territories with low population density and low productive indexes, was not only a reaction of Colombian government to the trauma that meant the separation of Panama from Colombia. That status, we argue, had also to do with the derogatory racial representations that historically weighed about this territory and its inhabitants. National officials, travelers and members of the political and intellectual elite of Colombia insisted that Chocó, for its majority black population, was a territory inhabited by savages that needed a sort of tutelage from the national government. We conclude that, faced with the process of marginalization that was built on the Intendency of the Chocó from the center of the country, some black and mulatto people, far from feeling marginal individuals, advanced actions and debates that were definitive in achieving the department status for this territory of the Pacific Coast.
\end{abstract}

Keywords:

Thesaurus: Autonomy, Afro-descendants, Race.

Author: Colombia, Chocó.

\section{Marginalizado, mas não marginal. Negros, mulatos e suas disputas por autonomia em Chocó, Colômbia (1903-1947)}

Resumo

Chocó foi caracterizado como um território com baixos níveis de autonomia política, econômica e administrativa. Sendo uma intendência e não um departamento, era eleitoralmente dependente de Antioquia, legalmente em Cauca e administrativamente em Bogotá. Neste artigo, analisamos os papéis dos líderes afrodescendentes na conquista de maiores níveis de autonomia para o Chocó na primeira metade do século XX. Sugerimos que o status de intendência não lhe foi atribuído somente por causa da separação do Panamá da Colômbia, mas também por causa das representações raciais depreciativas que pesavam sobre este território e seus habitantes. Autoridades nacionais, viajantes e membros da elite política e intelectual da Colômbia insistiram que Chocó era um território habitado por selvagens que necessitavam de uma espécie de tutela do governo nacional. Concluímos que seus habitantes negros, longe de se sentirem marginalizados, avançaram ações que foram definitivas para a conquista do status do departamento para este território.

Palavras-chave:

Tesauro: Chocó, Colômbia, autonomia, afro-descendentes, raça.

Autor: Colombia, Chocó. 


\section{Presentación}

El 27 de abril de 1926, estudiantes universitarios procedentes del ahora Departamento de Chocó y residentes en la ciudad de Medellín organizaron un centro cívico conocido como Liga Pro-Chocó. Uno de los integrantes de la citada liga era Diego Luis Córdoba (1907-1964), un estudiante negro que para entonces iniciaba su formación como abogado en la Universidad de Antioquia. El mismo Córdoba, en calidad de presidente de la naciente organización, explicó las razones por las cuales habían creado la liga. "La colonia chocoana, de esta ciudad, secundada por varios intelectuales antioqueños, inauguró solemnemente la Liga Pro-Chocó, con el fin de hacer conocer nuestro terruño y sus necesidades, buscándole progreso efectivo", informaron a través de un comunicado reproducido por el diario ABC. ${ }^{1}$

La liga que presidió Diego Luis Córdoba y los objetivos que perseguía la misma reflejan el sentimiento de búsqueda de autonomía política, económica y territorial que tomó fuerza entre profesionales, estudiantes y políticos de diferentes regiones colombianas durante la primera mitad del siglo XX. La historiografía colombiana ha estudiado con detenimiento las razones que dieron origen al surgimiento de estos discursos de autonomía regional. Los estudios, inicialmente, se concentraron en revisar el impacto del manejo centralista del poder en el desigual desarrollo económico y social que, en comparación con el centro del país, registraron las regiones colombianas. ${ }^{2}$

Luego, tras la recuperación de la historia política y sus preocupaciones por las acciones de los sectores subalternos, emergieron reflexiones centradas en los liderazgos políticos y sus disputas por lograr mayores niveles de autonomía para los espacios regionales. ${ }^{3}$ Recientemente, a la luz de los estudios culturales, varios investigadores han enfatizado en el peso que las representaciones raciales han tenido en la reproducción de las desigualdades sociales existentes en espacios de fronteras, mayoritariamente habitados por sectores negros e indígenas. ${ }^{4}$ Exceptuando

\footnotetext{
1"Se instala en Medellín una Liga Pro-Chocó", $A B C$, Quibdó, abril 27 de 1926.

${ }^{2}$ Adolfo Meisel Roca: “¿Por qué se disipó el dinamismo industrial de Barranquilla?”, Lecturas de Economía 23 (1987), 57-84.

${ }^{3}$ Pietro Pisano, Liderazgo político 'negro' en Colombia, 1943-1964 (Bogotá: Universidad Nacional de Colombia, Facultad de Ciencias Humanas, 2012); Helg, Aline, Liberty and Equality in Caribbean Colombia 1770-1835 (Chapel Hill: University of North Carolina Press, 2004); Múnera, Alfonso, El fracaso de la nación. Región, raza y clase en el Caribe colombiano, 1717-1810 (Bogotá: editorial Planeta, 1998); Posada Carbó, Eduardo, "La liga costeña, una expresión de poder regional”, Boletín Cultural y Bibliográfico 22:3, 1985.

${ }^{4}$ Claudia Leal, Landscape of Freedom. Building a Postemancipation Society in the Rainforest of the Western Colombia (Tuscon: University of Arizona Press, 2018); Appelbaum, Nancy, Mapping the Country of Regions. The Chorographic Commission of Nineteenth-Century Colombia (Chapell Hill: University of North Carolina Press, 2016); Appelbaum, Nancy, Muddied Waters: Race, Region, and Local History in Colombia (Durham: Duke University Press, 2003); Pérez, Amada, Nosotros y los otros. Las representaciones de la nación y sus habitantes, 1880-1910 (Bogotá: Universidad Javeriana, 2015); Hernández, Juan, "La chocoanidad en el siglo XX: representaciones sobre el Chocó en el proceso de departamentalización (19131944) y en los movimientos cívicos de 1954 y 1987”, (Tesis de pregrado), Universidad Javeriana, 2010; Flórez Bolívar, Francisco Javier, "Representaciones del Caribe colombiano en el marco de los debates sobre
} 
las recientes investigaciones de la historiadora Sharika Crawford sobre las islas de San Andrés y Providencia, ${ }^{5}$ pocos esfuerzos se han realizado para integrar esta triple mirada en una perspectiva holística que, al tiempo que articule lo económico, lo político y lo cultural, ponga en el centro de las disputas por la autonomía regional de comienzos del siglo XX a los habitantes negros y mulatos.

Este texto, con esta perspectiva en mente, estudia el rol que jugaron líderes de origen afrodescendiente ${ }^{6}$ en la consecución de mayores niveles de autonomía para el Chocó. Pretende responder dos preguntas estrechamente interrelacionadas: i) ¿qué factores políticos, raciales y económicos incidieron en la poca autonomía que Chocó mantuvo durante la primera mitad del siglo XX?; y ii) ¿qué narrativas y acciones (individuales y colectivas) adelantaron habitantes negros y mulatos de Chocó por lograr mayores niveles de autonomía? El texto muestra que la búsqueda de la citada autonomía guardaba relación con el estatus de intendencia nacional que mantuvo este territorio durante buena parte de la primera mitad del siglo XX. Ese estatus, reservado a territorios con poca densidad poblacional y bajo índices productivo, se le asignó al Chocó en el marco del trauma que significó la separación de Panamá de Colombia.

Ese sentimiento de autonomía también estaba en estrecha conexión con las múltiples representaciones que pesaban sobre el Chocó. Funcionarios nacionales, viajeros y miembros de la élite política e intelectual de Colombia insistían en que Chocó, por su mayoritaria población negra, era un territorio habitado por salvajes que necesitaba de una suerte de tutelaje de parte del gobierno nacional. Líderes negros y mulatos adelantaron acciones y debates que le permitieran al Chocó convertirse en Departamento. Estos sectores articularon una narrativa que pretendió deslegitimar las visiones despectivas que se construyeron sobre el Chocó y sus habitantes como bárbaros e incivilizados.

la degeneración de las razas: geografia, raza y nación a comienzos del siglo XX", en Historia y Espacio 31, 2008, pp. 35-59; Alarcon Meneses, Luis y Conde Calderón, Jorge, "Social Representations of National Territory and Citizenships in Nineteenth-Century History and Geography Textbooks of the Colombian Caribbean Region, Pedagógica Histórica: International Journal of the History of Education. Vol. XLIII, No 5, 2007; Múnera, Alfonso, Fronteras imaginadas. La construcción de las razas y la geografía en el siglo XIX colombiano, (Bogotá: Planeta, 2005); Arias Vanegas, Julio, Nación y diferencia en el siglo XIX colombiano. Orden nacional, racialismo y taxonomías poblacionales (Bogotá, Uniandes/Ceso, 2005); Serje, Margarita, El revés de la nación. Territorios salvajes y tierras de nadie (Bogotá: Uniandes-CESO, 2005); Roldan, Mary, A sangre y fuego. La violencia en Antioquia, Colombia 1946-1953 (Bogotá, ICANH/ Fundación para la promoción de la Ciencia y la tecnología, 2003); Steiner, Claudia, Imaginación y poder: el encuentro del interior con la costa en el Urabá, 1860-1900 (Medellín, Universidad de Antioquia, 2003); Wade, Peter, Music, Race and Nation: Música Tropical in Colombia (Chicago: University of Chicago Press, 2000); Wade, Peter, Blackness and Race Mixture. The Dynamics of Racial Identity in Colombia (Baltimore: John Hopkins University Press, 1993).

${ }^{5}$ Sharika Crawford, "Panama Fever: Colombian Fears of Secession on San Andrés and Providencia Islands, 1903-1913", The Global South 2, Interoceanic Diasporas and The Panama Canal's Centennial (Fall 2012), $15-38$.

${ }^{6}$ Los censos que se hicieron a comienzos del siglo XX $(1912,1918)$ hablaban de negros y mezclados, y no de afrodescendiente. Por tanto, en este texto utilizo el término afrodescendiente como categoría de análisis para designar a las personas que abiertamente reconocían su pertenencia a la raza negra, o aquellos que, sin autoidentificarse racialmente, eran descritos como negros o mulatos. 


\section{La secesión de Panamá y sus efectos sobre Chocó}

Durante las primeras décadas del siglo XX, tras la separación de Panamá de Colombia (1903), el temor de que el voraz apetito imperialista de Estados Unidos se extendiera a otros territorios nacionales se apoderó del gobierno colombiano. Las autoridades, como lo demostró recientemente la historiadora Sharika Crawford, temían que con la construcción del Canal de Panamá varios espacios fronterizos terminaran en manos del gobierno estadounidense, liderado para entonces por el presidente republicano Theodore Roosvelt. Según Crawford, ese justificado temor obedecía, en casos como el de San Andrés y Providencia, a la cercanía de estas islas del Caribe colombiano con Panamá, a la presencia creciente de inversores norteamericanos en las mismas y al mayor vínculo que tenían con el Gran Caribe que con la parte continental colombiana. ${ }^{7}$

Chocó, ubicado en la costa Pacífica de Colombia, fue otro de los territorios que reunía algunas de las circunstancias que tanto temor despertaban en las autoridades colombianas. Se encontraba alejado de la paramuna capital (Bogotá) y compartía con Panamá una extensa frontera. Empresarios estadounidenses, atraídos por el resurgir de la minería chocoana en el tránsito del siglo XIX al XX, también realizaron inversiones en este territorio. La declaratoria del gobierno colombiano de la libre explotación de platino a partir de 1907 hizo que varios de esos inversionistas constituyeran firmas dedicadas a esta actividad, siendo la compañía Chocó-Pacifico la que mayor control ejerció sobre la actividad minera. Y lo hizo en un contexto en el que, gracias a la caída de la producción de este metal en los Urales como consecuencia de la Revolución Rusa, Colombia se convirtió en el mayor productor mundial de platino. Del Chocó hacia Cartagena o Buenaventura salía el platino que la Chocó-Pacífico obtenía a través del dragado de los lechos de los ríos que bañaban las provincias del Atrato y San Juan. ${ }^{8}$ Estas dos circunstancias, aunadas a la poca inversión que el Estado colombiano hacía en el Chocó, podían dar forma a la tormenta perfecta para que habitantes de este territorio se sintieran seducidos a anexarse a la nueva nación panameña.

La respuesta del gobierno colombiano, en cabeza del general Rafael Reyes (1905-1909), no se hizo esperar. Con el I took Panamá de Roosevelt retumbando en sus oídos, Reyes buscó ejercer un mayor control sobre los territorios que integraban a la ya cercenada nación. A través de dos reformas a la constitución de 1886, realizadas en 1905 y 1908 respectivamente, el presidente fragmentó los nueve grandes departamentos existentes desde 1886 y los convirtió en veintiséis. También creó los llamados territorios nacionales, conformados por intendencias y comisarias. En este contexto, las Provincias de San Juan y del Atrato, que pertenecían al Departamento

\footnotetext{
${ }^{7}$ Crawford 21.

${ }^{8}$ Claudia Leal, "La compañía minera Chocó-Pacífico y el auge del platino en Colombia, 1897-1930", Historia Critica (noviembre 2009) 150-164.
} 
del Cauca, fueron separadas de este y dieron forma a la Intendencia Nacional del Chocó en 1907. Un año más tarde, Reyes fue más lejos al crear el Departamento de Quibdó con la ciudad del mismo nombre como capital. ${ }^{9}$

Carlos E. Restrepo, quien sucedió al general Reyes en la presidencia de Colombia, también implementó medidas tendientes a disipar cualquier asomo de secesión en otros territorios colombianos. A San Andrés y Providencia, por ejemplo, envió tropas a resguardar la frontera y, sobre todo, desvinculó administrativa y políticamente las mencionadas islas del Departamento de Bolívar y las convirtió en una intendencia nacional. ${ }^{10}$

La pretensión del presidente de la República de ejercer un mayor control sobre los territorios de frontera lo llevó, en 1910, a establecer que para ser departamento las entidades territoriales debían tener, entre otras cosas, no menos de 250.000 habitantes y $\$ 250.000$ oro de renta anual. Los espacios que no cumplían con esos requisitos dependían -sin mediación de gobernadores o diputados- del presidente de la República. ${ }^{11}$ Chocó no cumplía con ninguno de los dos requisitos. Aún en 1918, según el censo levantado ese año y registrado por la Gaceta de la Intendencia, en el entonces territorio chocoano sólo habitaban 69.335 habitantes. Y la renta anual, pese al progresivo crecimiento que estaba presentando la explotación de platino, no alcanzaba esos guarismos

Esta infortunada combinación de circunstancias hizo que Chocó perdiera de manera automática su corta condición de departamento y se convirtiera nuevamente en intendencia. Este estatus, aunque le permitió "librarse" relativamente del dominio político y el control económico que sobre este territorio ejercían los descendientes de las familias esclavistas caucanas, implicaba unas limitaciones de orden político que dejaban sin resolver el espinoso tema de la autonomía. Al dejar de ser Departamento, carecía de Asambleas y por tanto de diputados que se encargaran de exponer los problemas regionales a los congresistas. Dada su baja densidad poblacional, no gozaba de la posibilidad de tener senadores que gestionaron recursos para el desarrollo de su territorio. El intendente, máxima autoridad administrativa, era nombrado directamente por el presidente de la república.

El estatus de intendencia también le restaba autonomía en materia económica. El hecho de que el presidente de la república fuera quien definiera el gasto del presupuesto de la intendencia dificultaba el buen funcionamiento de la administración pública. Las obras y acciones que se debían priorizar no se realizaban al ritmo que los habitantes del Chocó esperaban. Esta realidad se hizo evidente en la buena marcha de

\footnotetext{
9 Juan Hernández, "La chocoanidad en el siglo XX: representaciones sobre el Chocó en el proceso de departamentalización (1913-1944) y en los movimientos cívicos de 1954 y 1987”. Tesis de pregrado, Universidad Javeriana (2010), 14-16.

${ }^{10}$ Crawford 24-26.

${ }^{11}$ Hernández 18-19.
} 
la educación y en las instituciones educativas con las que contaba Quibdó. La capital del territorio que hizo que Colombia entre 1916 y 1924 se convirtiera en el mayor productor de platino en el mundo carecía de una institución educativa pública que garantizara la formación secundaria a sus habitantes. La única existente, la Escuela Modelo, era para varones y sólo ofrecía la posibilidad de cursar hasta cuarto año de primaria. Las restantes, El Colegio Carrasquilla para varones, y el Colegio de la Presentación para mujeres eran de carácter privado. ${ }^{12}$

A estas limitaciones de autonomía política y económica se le sumaban otras de orden administrativo que dificultaban la consolidación de la unidad territorial del Chocó. El estatus de intendencia era de carácter transitorio y por tanto el congreso de la república -vía decreto- podía modificar su composición territorial. Las élites comerciales y políticas de los Departamentos de Cauca, Caldas y Antioquia, conocedores de las riquezas comerciales y minerales que caracterizaban a las provincias de San Juan y del Atrato, vieron en las mismas la posibilidad de consolidar sus economías. Y, sobre todo, entendían que la cercanía de Chocó con Panamá convertía su territorio en un punto estratégico en la reconfiguración que estaba experimentando la geografía comercial con la apertura del canal que interconectaba al Atlántico con el Pacífico.

De manera que -en repetidas ocasiones- las citadas élites solicitaron al congreso de la república la desmembración de la Intendencia del Chocó y la anexión de algunas de las dos provincias a sus respectivos departamentos. Este adverso cuadro de limitaciones políticas, económicas y territoriales, que le impedían a Chocó obtener el estatus de departamento, como veremos, se complejizaba más por el impacto que las ideas del racismo científico tuvieron en Colombia durante las cuatro primeras décadas del siglo $\mathrm{XX}$.

\section{Habitantes de una geografía tropical}

Entre 1910 y 1945, discursos que hablaban de la nula presencia de civilización en el trópico y de la natural y biológica inferioridad de las personas de origen afrodescendiente impactaron en Colombia. ${ }^{13}$ Chocó reunía dos condiciones que, a los ojos de los defensores de las ideas del racismo científico imperante, hacían improbable cualquier posibilidad de progreso en ese territorio y ubicaba a sus habitantes en un estatus de natural inferioridad: era una zona tropical y estaba habitado mayoritariamente por sectores negros y mulatos.

\footnotetext{
12 Claudia Leal, Black Forests. The Pacific Lowlands of Colombia, 1850-1930. (Tesis doctoral) University of California, 2004.

13 Francisco Javier Flórez Bolívar "Representaciones del Caribe colombiano", Eduardo, Restrepo, "Imágenes del "negro" y nociones de raza en Colombia a principios del siglo XX", Revista de Estudios Sociales 27, 2007, pp. 46-61; Jason, McGraw, "Purificar la nación: eugenesia, higiene y renovación moralracial de la periferia del Caribe colombiano, 1900-1930”, Revista de Estudios Sociales № 27, 2007, pp. 62-75; Álvaro Villegas Vélez, "Raza y nación en el pensamiento de Luís López de Mesa: Colombia, 1920 1940", Estudios Políticos 26, 2005, pp. 209-232; Helg, Aline, "Los intelectuales frente a la cuestión racial en el decenio de 1920: Colombia entre México y Argentina”, Estudios sociales 4, 1989.
} 
La alta presencia de habitantes de este origen racial en Chocó obedece al pasado esclavista del citado territorio. Muchos de los hombres y mujeres esclavizados que -procedentes de África- ingresaron a través del puerto de Cartagena tuvieron como destino final Quibdó. Pero, sobre todo, la gran mayoría de los sometidos a esclavitud terminaban siendo utilizados por sus propietarios en los centros mineros que se encontraban en las provincias del Atrato y San Juan. En 1782, estas dos provincias, que daban forma a la gobernación del Chocó, contaban con 7.088 esclavos. Este número de esclavizados convirtió al Chocó en el primer suministrador del oro que se exportó desde la Nueva Granada durante el siglo XVIII, y transformó un territorio habitado originariamente por indígenas en un espacio de mayorías negras y mulatas. ${ }^{14}$

Al iniciarse el siglo XX, las huellas de ese pasado esclavista se evidenciaban en la composición demográfica de Chocó. En 1912, las provincias de San Juan y el Atrato contaban con 57.606 habitantes, de los cuales el 70.6\% (40.661) eran negros y $15.6 \%$ (8.989) mezclados. El restante $13.8 \%$ de la población lo integraban, en su orden, indígenas (5.237) y blancos (2.719). ${ }^{15}$ El protagónico rol de estos habitantes negros y mulatos en el mundo laboral del Chocó era indiscutible. El censo de 1918 muestra que las provincias del Atrato y San Juan tenían una PEA de 43.478 personas. En la estructura socio-ocupacional del Chocó, las personas dedicadas a la industria agrícola eran el grupo más representativo. De los 24.543 individuos que estaban vinculados a la explotación de materias primas, entre ellas tagua y caucho, 14.163 eran negros. ${ }^{16}$ También mostró que en ambas provincias había 6.153 hombres y 4.234 mujeres vinculadas a la minería. De esas 10.387 personas, 9.167 eran negras, 1148 mezcladas, y 252 blancas. ${ }^{17}$ En su mayoría se trataba de personas que, haciendo uso de las técnicas el mazamorreo o el buceo en los cauces de los ríos, extraían de manera artesanal el oro. Algunos, como los casos de Antonio Asprilla o Zabulón Córdoba, en el marco de la ola de especulación que se generó con la declaratoria de la libre explotación de platino, solicitaron títulos y se convirtieron en pequeños mineros. Otros, alquilaban minas en las terrazas aluviales de donde extraían el platino y oro que vendían a comerciantes locales encargados de exportarlo.

Después de la agricultura y la minería, el servicio doméstico era otra actividad desempeñada mayoritariamente por habitantes negros. El referenciado censo registró 3.441 personas como sirvientes, siendo las mujeres (1.550) y hombres (935) de origen afrodescendiente quienes mayoritariamente se dedicaban a esta actividad. Luego seguían los bogas, encargados de movilizar las embarcaciones que surcaban las aguas

\footnotetext{
${ }^{14}$ Bernardo Leal, "Matar a los blancos bueno es, luego Chocó acabará: cimarronaje de esclavos jamaiquinos en el Chocó", Fronteras 2:2, 1998, p. 147; Sharp, William, "La rentabilidad de la esclavitud en el Chocó", Hispanic American Historical Review 55:3, agosto 1975, p. 21.

15 “Censo de la Intendencia Nacional del Chocó año de 1912”, Gaceta de la Intendencia, Quibdó, 10 de julio de 1912.

16 "Censo levantado el 14 de octubre de 1918”, $A B C$, Quibdó, 15 de noviembre de 1926.

17 “Censo levantado el 14 de octubre de 1918”, $A B C$, Quibdó, 15 de noviembre de 1926.
} 
del circuito comercial conformado por la Intendencia, Cartagena y la Provincia del Sinú. De los 2.519 bogas con que contaba el Chocó y que movían 1.760 eran negros, 528 mulatos, 321 indígenas, y ninguno era blanco. ${ }^{18}$

El rol de los sectores negros y mulatos en el movimiento comercial y económico que se generó en Chocó a través de la exportación de tagua, caucho y platino iba más allá de la recolección de estos productos, de la práctica del mazamorreo en los centros mineros y de su desempeño como bogas o sirvientes. Aunque el monopolio del gran comercio lo tenían empresarios extranjeros (sirios, libaneses, italianos) y nacionales (cartageneros y miembros de la élite blanca chocoana), ${ }^{19}$ los negros y mulatos, en conjunto, eran quienes mayoritariamente se dedicaban a esta actividad. Según el censo de 1918, de los 1.586 comerciantes que había en Chocó para ese año, 864 eran de origen afrodescendiente, mientras los restantes 715 eran blancos. ${ }^{20}$

Varios de los estudiantes que egresaron del Colegio Carrasquilla se desplazaron hacia Medellín, Bogotá, Cali y Popayán para formarse en los centros universitarios de estas ciudades. ${ }^{21}$ Cuatro de los más activos y visibles en los años veinte fueron Diego Luis Córdoba, Adán Arriaga Andrade, Manuel Mosquera Garcés y Juan B. Córdoba, quienes se formaron como abogados. Esta generación contribuyó a aumentar el reducido número de profesionales con que contaba la Intendencia del Chocó. Según el censo de 1918, en todo el territorio chocoano escasamente había veintiocho profesionales; de los cuales veintitrés eran blancos, dos negros y tres mulatos. ${ }^{22}$ Entre estos cinco profesionales afrodescendientes, se destacaba Reinaldo Valencia Lozano, abogado, periodista, y director del ABC, el principal diario de Chocó. ${ }^{23}$ A Valencia Lozano, se le sumaba Gregorio Sánchez Gómez, abogado y autor de varias novelas sobre la realidad racial, cultural y económica del Chocó. ${ }^{24}$

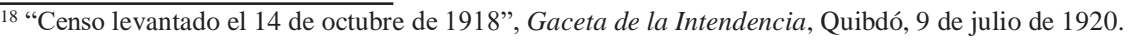

19 Ana Milena Rhenals reconstruye la presencia de empresarios extranjeros y nacionales en su estudio sobre el circuito comercial existente entre la Provincia del Sinú, Cartagena y el Atrato. Rhenals Doria, Ana Milena (2013), Del ideal europeo a la realidad árabe. Inmigrantes sirio-libaneses en el circuito comercial entre Cartagena, el Sinú y el Atrato (Colombia), 1880-1930 (Tesis doctoral), Universidad Pablo de Olavide.

20 "Censo levantado el 14 de octubre de 1918”, Gaceta de la Intendencia, 17 de abril de 1910.

${ }^{21}$ Algunos de estos profesionales, conocida como la Generación del Carrasquilla, es estudiada por Luis Fernando González, Quibdó: Contexto histórico, desarrollo urbano y patrimonio arquitectónico (Medellín: Universidad Nacional de Colombia, 2003), 183-184.

22 "Censo levantado el 14 de octubre de 1918", Gaceta de la Intendencia, 27 de julio de 1926.

${ }^{23}$ En 1923, en el marco de unas descripciones realizadas por el ingeniero Jorge Álvarez Lleras sobre las clases sociales existentes en el Chocó, Valencia Lozano se incluyó entre las personas de origen afrodescendiente. Álvarez Lleras señaló que la primera clase estaba conformada por una gran masa de negros pobres; la segunda integrada por negros y mulatos que poseen algunos medios de subsistencia, y la tercera compuesta por los extranjeros con intereses comerciales e industriales en la región. Refiriéndose a esta caracterización, Reinaldo Valencia expresó que, en el segundo grupo social, es decir, el de los negros y mulatos con ciertos recursos, "quizá quedamos clasificados más de cuatro". "Entrevista con el doctor Jorge Álvarez Lleras”, ABC, Quibdó, 1 de agosto de1923.

${ }^{24}$ Gregorio Sánchez Gómez fue incluido recientemente en la biblioteca de literatura afrocolombiana editada por el Ministerio de Cultura.
} 
Sobre el territorio chocoano y su variado grupo de habitantes de origen afrodescendiente recayeron un conjunto de representaciones negativas. Este territorio, al igual que otros espacios con economías de enclave, experimentó lo que la historiadora Marixa Lasso recientemente conceptualizó como "the disconnection of tropical spaces and populations therein from notions of modernity". Lasso, a partir del estudio de las representaciones que distintos actores sociales construyeron sobre la ciudad de Colón (Panamá) y su población afroantillana, sugiere que esa desconexión fue producto de una narrativa sobre los enclaves que emergió en el tránsito del siglo XIX al XX. Según Lasso, "these narratives not only "distanced tropical workers and places from the global economies and modern technologies they had helped to create". Estas narrativas también "obscured the fact that enclaves were some of the most cosmopolitan towns in the Americas, as well as centers of twentieth-century industrial innovation in agriculture, mining, and transportation". ${ }^{25}$

En los territorios de la actual Colombia la previamente citada desconexión, aunque empezó a tomar forma desde finales del siglo XVIII, ${ }^{26}$ se afianzó en la segunda mitad del XIX. Según Nancy Appelbaum, entre 1850 y 1885 las elites intelectuales colombianas adscribieron jerarquías a los componentes regionales de la nación, construyendo ciertas regiones como superiores en términos raciales y morales. ${ }^{27}$ Escritores como los hermanos José María y Miguel Samper, por ejemplo, hablaron de la existencia de una supuesta jerarquía territorial, que implicaba la presencia de un centro andino naturalmente superior gracias a la presencia mayoritaria de sectores blancos y a las condiciones favorables del clima en los altiplanos. En contraste, las costas, habitadas por negros y caracterizadas por su clima tropical malsano, estaban condenadas al atraso y a la total ausencia de vida civilizada. ${ }^{28}$

Estas imágenes emergieron una y otra vez en el marco de los debates sobre la degeneración de la raza colombiana que tuvieron lugar en Cartagena y Bogotá, en 1918 y 1920 respectivamente. Diversos apartes de las conferencias presentadas por Miguel Jiménez López y Luis López de Mesa así lo ratifican. Luego de recordar cómo diversas culturas sucumbieron o se extinguieron bajo la "acción del clima devorador del África Septentrional”, Jiménez López subrayó las influencias ambientales y los obstáculos del trópico en los procesos evolutivos de las regiones y sus habitantes:

... parece demostrado que las razas superiores, aquellas que están llamadas a una cultura intensa no pueden hallar aclimatación ni son capaces de florecimiento en las zonas templadas; bajo el trópico, decaen y desaparecen en breve, y quizá este hecho confirme, una vez más, la vieja creencia de que la humanidad tuvo su origen en lugares situados por encima de la línea equinoccial. ${ }^{29}$

\footnotetext{
${ }^{25}$ Marixa Lasso, "Nationalism and Immigrant Labor in a Tropical Enclave: the West Indians of Colon City, 1850-1936”, Citizenship Studies, 17:5, (2013), 556.

${ }^{26}$ Alfonso Múnera, Fronteras imaginadas. La construcción de las razas y la geografía en el siglo XIX colombiano (Bogotá: Planeta, 2005).

27 Appelbaum, Nancy, Muddied Waters: Race, Region, and Local History in Colombia (Durham: Duke University Press, 2003), 16 - 26.

${ }^{28}$ Alfonso, Fronteras imaginadas.

${ }^{29}$ Miguel Jiménez, Nuestras razas decaen. Algunos signos de degeneración colectiva en Colombia y en
} 
Luis López de Mesa, por su parte, afirmó que en Colombia estaba presente una configuración bipolar del territorio, donde el eje se encontraba en el altiplano, bastante alejado de los valles y costas ardientes, así como de las zonas bajas y tropicales, lo cual explicaba el atraso de todos estos espacios tan distantes del "centro de gravedad de la conducta del pueblo colombiano". ${ }^{30}$ Las élites colombianas, entonces, dieron forma a un imaginario nacional que, parafraseando al antropólogo británico Peter Wade, perseguía un ideal de homogeneidad racial y, a la vez, establecía jerarquías regionales a partir de categorías raciales y culturales. ${ }^{31}$

En el marco de los debates sobre la degeneración de las razas, la región pacífica, en general, y el territorio chocoano, en particular, sintieron el peso de esas jerarquías regionales y raciales que las élites colombianas habían logrado construir. El resultado de esa suerte de geografía racializada de la nación fue la elaboración de una serie de representaciones que cimentaron la idea del Chocó como un espacio condenado al atraso y a la ausencia de progreso y civilización. ${ }^{32}$

Viajeros, agentes consulares, funcionarios nacionales y miembros de élite local, amparados en ideas que definían los trópicos como zonas insalubres y mal sanas, contribuyeron a construir este conjunto de imágenes negativas sobre el Chocó. Louis G. Dreyfus, un agente consular de los Estados Unidos en Quibdó, fue uno de los que se detuvo a hablar de las dificultades e incomodidades que caracterizaban a este espacio. En uno de sus reportes oficiales a Washington, Dreyfus no dudó en incluir los mosquitos y sus picaduras, de las cuales "estaba cubierto de pies a cabeza" ${ }^{33}$ Bernardo Merizalde del Carmen, un monje agustiniano que hizo presencia en la costa Pacífica en los años veinte, también reforzó esta imagen. Merizalde del Carmen sintetizó sus actividades de misionero en el Chocó como una lucha constante en contra de "las nubes de mosquitos, los reptiles venenosos, y lo que es peor, la apatía e ignorancia de los negros". 34

La alta presencia de habitantes negros, considerados ignorantes e inferiores, precisamente, fue otro de los argumentos utilizados para construir la imagen del Chocó como un espacio alejado de las bondades de la civilización. Los comentarios tendían a animalizar el comportamiento de los habitantes de la intendencia. Un ingeniero bogotano, Jorge Álvarez Lleras, hizo una caracterización que permite sustentar lo anotado. Álvarez Lleras, comisionado por el gobierno nacional para hacer un estudio de las vías de comunicaciones del Chocó, visitó algunos de sus distritos en el año

\footnotetext{
los países similares. El deber actual de la ciencia (Bogotá: Imprenta y Litografía de Juan Casis, 1920), 35.

${ }^{30}$ Luis López de Mesa, Escrutinio sociológico de la historia colombiana (Bogotá: Academia colombiana de historia. Segunda edición, (1956), 279.

${ }^{31}$ Peter Wade, Music, Race and Nation: Música Tropical in Colombia (Chicago: University of Chicago Press, 2000), 5.

${ }^{32}$ Appelbaum, Mapping the Country of Regions; Claudia, Black Forests; Peter, Blackness and Race Mixture.

${ }^{33}$ Leal, Black Forests.

${ }^{34}$ Bernardo, Merizalde del Carmen, Estudio de la costa colombiana del Pacífico (Bogotá: Imprenta del estado mayor general, (1921)).
} 
de 1923. A su regreso a Bogotá, dio una entrevista al Diario Nacional en la que describió las clases sociales que era posible distinguir. En esta entrevista, reproducida con indignación por el $\mathrm{ABC}$, sostuvo que la clase mayoritaria era la de los negros, a quienes describió como "pobres bestias humanas, desamparadas de toda educación, en la pobreza más punzante, en una insipiencia mental que más se avecina al animal irracional que a este otro que llaman civilizado". ${ }^{35}$

Los habitantes del Chocó para ser incorporados a la nación debían sufrir un proceso de tutelaje moral. Ese tutelaje fue encomendado a misioneros franceses y españoles, quienes a partir de 1909 iniciaron actividades de adoctrinamiento y educación con el propósito de disminuir la brecha que separaba a la mayoritaria población negra del Chocó de su supuesto estado de 'irracionalidad" . ${ }^{36}$ Desde Bogotá, algunos congresistas defendían y consideraban necesaria la presencia de las citadas misiones en este territorio porque estaban "llevando allí la civilización con la insignia de la cruz". ${ }^{37}$

La introducción de inmigrantes europeos también fue contemplada como posible solución para lograr que los habitantes del Chocó salieran del estado de "insipiencia mental" en la que supuestamente se encontraban. A tono con los debates sobre inmigración que tuvieron lugar en Latinoamérica entre 1880 y $1930,{ }^{38}$ varios de las personas que estuvieron en Chocó también hablaron de la necesidad de mezclar su mayoritaria población negra con inmigrantes procedentes de Europa. ${ }^{39}$ Este fue el caso del escritor Pedro Sonderéguer, quien en varias oportunidades propuso una inmigración selectiva que contribuyera al progreso de Quibdó y el Atrato en general. En 1926, en una carta enviada desde Argentina al político conservador Jorge Valencia Lozano, Sonderéguer sugirió la entrega y distribución de terrenos baldíos para atraer inmigrantes. Eso suponía, además, "desarrollar una intensa e inteligente propaganda" no sólo a través de medios nacionales, sino por medio de la prensa de ciudades como la Habana. Esta ciudad ameritaba especial atención, aseguraba este escritor, porque en ella "hay muchos españoles". ${ }^{40}$

Un año después, en una de sus novelas que tuvo como escenario Quibdó, este autor, al tiempo que habló de la incapacidad de los habitantes negros del Chocó para abanderar el desarrollo de su territorio, dejó entrever su identificación con los planes selectivos de inmigración. "Nosotros necesitamos traer inmigrantes europeos para mezclarlos con los nativos", dice uno de los personajes de la novela luego de ver a varios jóvenes negros desnudos a orillas de un río. ${ }^{41}$

\footnotetext{
35 "Entrevista con el doctor Jorge Álvarez Lleras", $A B C$, Quibdó, 1 de agosto de 1923.

${ }^{36}$ Leal, Black Forests.

37 "El gran debate sobre las misiones", $A B C, 21$ de noviembre de 1918.

${ }^{38}$ George Reid, Andrews, Afro-Latin America, 1800-2000, (New York: Oxford University Press, 2004); Richard Graham, (Ed); The Idea of Race in Latin America, Austin: Texas University Press, 1990.

${ }^{39}$ Ana Milena, Del ideal europeo a la realidad árabe.

40 "Pedro Sonderéguer y el desarrollo del Atrato", $A B C$, Quibdó, 21 de abril de 1926.

${ }^{41}$ Pedro Sonderéguer, Quibdó (Buenos Aires: hermanos Maucci, 1917).
} 
Miembros de la élite chocoana reprodujeron algunos de estos discursos sobre la necesidad de introducir inmigrantes europeos para superar la supuesta inferioridad de los sectores de origen afrodescendiente. Entre 1910 y 1930, aparecen registros de prensa que permiten sustentar lo anotado. En 1927, una editorial del diario El Gráfico, ante el escaso número de habitantes con los que contaba el Chocó, sugirió que era "tiempo de seleccionar y de encauzar debidamente la corriente migratoria que tímidamente llama a nuestras puertas como una promesa de prosperidad o como un augurio de grandes males". ${ }^{42}$ Ese mismo año, desde el periódico La Aurora, plantearon que el gobierno debía garantizar las condiciones necesarias para que llegaran al Chocó inmigrantes considerados "superiores". "La política necesita contemplar nuestro problema migratorio, preparando el terreno a la selección, por las buenas oportunidades y las seguridades que ofrezcan al inmigrante de tipo superior", afirmaba un editorial del citado periódico". ${ }^{43}$

De manera que las riquezas comerciales y auríferas del Chocó, la fuerza laboral que contribuyó a convertirlo por varios años en el mayor productor de platino en el mundo, la conexión que mantenía con centros metropolitanos como Inglaterra y Estados Unidos y la trayectoria académica que estaban construyendo sus habitantes se perdían en caracterizaciones que insistían en su clima mortífero y en la presencia de insectos. Su población negra -considerada inferior- habitaba un territorio supuestamente alejado de la civilización, cuya única posibilidad de "redención" era la introducción de inmigrantes europeos y/o los buenos oficios de misioneros extranjeros. Sin embargo, la redención del Chocó, como veremos, la hicieron sus mismos habitantes, siendo los sectores negros y mulatos uno de los protagonistas en ese proceso.

\section{4. "Hagámosle saber que los negros también piensan"}

Sectores afrodescendientes jugaron un papel central en el proceso de repensar el conjunto de representaciones negativas que distintos actores sociales construyeron sobre el Chocó y sus habitantes en la primera mitad del siglo XX. Un paso central en esa dirección fue la creación del periódico ABC (1913), que fue fundado no sólo por Reinaldo Valencia (como la historiografía sobre Chocó ha sostenido hasta el momento), sino que también tuvo como fundador al minero negro Guillermo Henry Cuesta.

El ABC fue la tribuna utilizada para expresar sus visiones sobre lo que realmente era su territorio y su población. Una a una las caracterizaciones que mostraban al Chocó como espacio poco apto para la civilización fueron cuestionadas. Este esfuerzo implicó la elaboración de una narrativa que, en primer lugar, restó importancia a las imágenes que lo mostraban como un espacio lleno "de alfombras de serpientes y de nubes de mosquitos; de ranchos infelices construidos sobre cuatro estacas". Sugerían que era "realmente divertido, oírlos bufar contra el calor, ponderar la incomodidad de las habitaciones, la fealdad de nuestras mujeres, lo malsano del

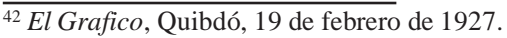

43 “La inmigración siria”, La Aurora, Quibdó, 14 de febrero de 1928.
} 
clima, la pobreza de nuestra alimentación". Esas caracterizaciones, concluían, eran "paparruchas, que ya han perdido la virtud de molestarnos, por lo muy repetidas que han sido, y por la poca autoridad moral de los sujetos que las dicen". ${ }^{4}$

En esta nueva narrativa, los sectores negros y mulatos se esforzaron también por construir unos referentes simbólicos que permitieran sustentar la existencia de tradiciones intelectuales y trayectorias políticas forjadas por los propios habitantes del Chocó. En diversos artículos, como lo resaltó el investigador Luis Fernando González, los columnistas del ABC describieron el rol que distintos personajes oriundos del Chocó habían jugado en la educación, la política y la vida militar de la región y el país. ${ }^{45}$ Artículos dedicados al poeta y político Cesar Conto (Quibdó, 1831- 1891), al pedagogo Ricardo Carrasquilla y al ex presidente de Colombia Manuel María Mallarino ocuparon varias de las páginas del ABC. ${ }^{46}$ Estudiantes negros que apenas iniciaban su formación secundaria en el Colegio Carrasquilla elaboraron pequeños ensayos que exaltaron a algunas de las figuras previamente citadas. En 1923, por ejemplo, Diego Luis Córdoba, en un texto sobre los hijos ilustres de Chocó, caracterizó a estos tres personajes como "una trinidad de estrellas de primera magnitud (que) destaca en el cielo del Chocó". ${ }^{47}$

El esfuerzo por construir esos referentes intelectuales y políticos hizo que algunos de los líderes negros y mulatos iniciaran debates sobre el verdadero lugar de nacimiento de algunas figuras destacadas en la política y la literatura a nivel nacional. El lugar de procedencia del escritor Jorge Isaacs (1837-1895) fue uno de los que dio pie a un apasionado debate entre miembros de la élite intelectual de Cali y los columnistas del ABC. Isaacs, hijo de un inmigrante procedente de Jamaica, fue el autor de María (1867), una de las primeras novelas publicadas en Colombia. Tradicionalmente se había aceptado que Isaacs había nacido en Santiago de Cali. En los años veinte, sin embargo, los chocoanos comenzaron a sugerir que su verdadero lugar de nacimiento era Quibdó. Uno de los primeros en plantear esa posibilidad fue Diego Luis Córdoba, quien en el previamente citado ensayo sobre los hijos ilustres del Chocó incluyó a Jorge Isaacs como uno de ellos. Al referirse al que para entonces era considerado el autor de la primera novela colombiana, Córdoba sostuvo "que nació en Quibdó y es chocoano por ende no obstante no decirlo así la Historia". ${ }^{48}$

Junto a estos políticos, educadores y escritores, pertenecientes a la élite blanca de Chocó, hubo en el $\mathrm{ABC}$, aunque en menor medida, espacio para figuras de origen afrodescendiente. Destacaron, por ejemplo, las hazañas militares del almirante

\footnotetext{
44 "Un huésped ingrato”, $A B C$, Quibdó, 29 de abril de 1924.

${ }^{45}$ Luis Fernando González, "Jorge Isaacs y la ruta del Caribe por el chocó. Memorias, comercio, esclavitud y modernidad", Memorias de Primer Simposio Internacional Jorge Isaacs el creador en todas sus facetas (Cali: Universidad del Valle, 2007), 337-347.

46 "Don Ricardo Carrasquilla", $A B C$, Quibdó, 23 de febrero de 1924; "Cesar Conto" y "Chocó", $A B C$, Quibdó, 28 de julio de 1923; "La fiesta de Cesar Conto", $A B C$, Quibdó, 21 de agosto de 1924.

47 "El Chocó", $A B C$, Quibdó, 25 de julio de 1923.

48 "El Chocó", $A B C$, Quibdó, 25 de julio de 1923.
} 
negro José Prudencia Padilla durante las guerras por la independencia de la corona española a comienzos del siglo XIX, y ponderaron la valentía del congresista Luis A. Robles al enfrentar insultos raciales en medio de un debate en los salones de la Cámara de Representantes a finales de la citada centuria. ${ }^{49}$

Los columnistas negros y mulatos a través de la construcción de esos referentes intelectuales y políticos aspiraban a lograr un doble propósito: primero, forjar un pasado y un presente tipificado por la existencia de liderazgos determinantes en el progreso y desarrollo del Chocó. El nombre de Chocó "figura en las páginas de la Historia de Colombia" no por obra de los misioneros franceses y españoles que llegaron a "civilizarlo". Era, más bien, el resultado de las acciones que, en este territorio, "cuna de hombres ilustres", habían adelantado sus destacados habitantes. "No se olvide que el Chocó ha dado a Colombia presidentes, poetas, literatos", señalaron desde el ABC. ${ }^{50}$ Segundo, buscaban cuestionar la supuesta incapacidad mental de los chocoanos en general y de los sectores afrodescendientes en particular. "Hagámosle saber que los negros también piensan", decía una de las primeras editoriales que se publicaron en el ABC..$^{51}$ La consecución de ambos propósitos - como veremos- sería central para alcanzar el objetivo que los habitantes del Chocó persiguieron de manera incesante durante la primera mitad del siglo XX: la declaratoria de Chocó como departamento.

\section{Las disputas por la departamentalización}

Los sectores afrodescendientes, conscientes de las limitaciones que suponía ser intendencia y de las implicaciones que tenía en sus realidades políticas, económicas y sociales, consideraron que la forma de superar tales limitaciones era logrando que su territorio retornara a su condición de Departamento. Varios de los argumentos expuestos por algunos de los líderes negros y mulatos para avanzar en esa dirección se pusieron en escena en 1918. Ese año, un conjunto de congresistas -procedentes de Bogotá y Antioquia- presentaron una propuesta que permitiera que Chocó dejara de ser intendencia nacional y asumiera el estatus de Departamento. ${ }^{52}$

Al tiempo que debatían la proposición en Bogotá, desde el ABC ambientaron una campaña para defender la consecución de ese propósito. El primer argumento expuesto se construyó en función de la separación de Panamá de Colombia. Desde la fundación del ABC, en 1914, proyectaron la imagen del Chocó como un territorio caracterizado por un fuerte patriotismo. Si Panamá era "traidor' y "rebelde", el que aspiraba a ser el nuevo departamento era "leal" y "patriota". Chocó "será dentro de poco, y con poco esfuerzo, otro Panamá rico", pero "leal y patriota, sin Huertas y Barón y sin nexos con ambiciosos extranjeros", ${ }^{53}$ señaló una editorial de 1914. Cuatro

\footnotetext{
49 "El bronce de Robles", $A B C$, Quibdó, 3 de octubre de 1918; "Fueron exhumados los restos del Almirante Padilla" ABC, Quibdó, 11 de julio de 1923.

50 "El periódico de Guillermo Camacho también falsea la verdad”, $A B C$, Quibdó, 10 de enero de 1923.

51 “Alrededor de un informe", $A B C$, Quibdó, 30 de septiembre de 1914.

52 “Proyecto de ley por el cual se organiza el territorio del Chocó”, $A B C$, Quibdó, 21 de septiembre de 1918.

53 "El Chocó", $A B C$, Quibdó, 28 de junio de 1914.
} 
años después, en el marco de los debates que estaban teniendo lugar en Bogotá, volvió a hacer uso de estos argumentos. En esta oportunidad, reprodujo un artículo en el que su autor, amparado en el patriotismo de los chocoanos, insistía en que el gobierno colombiano debía adelantar una reforma constitucional que facilitara la declaratoria del Chocó como Departamento para evitar que el mismo fuera "materia digerible del vientre rosveltiano". Su "excepcional posición orográfica, con costas en ambos mares y su proximidad a la arteria mundial del Canal de Panamá, convierten al Chocó en bocado apetitoso para el paladar insaciable del Coloso Unido". La solución era declararlo Departamento, garantizándole al gobierno la existencia de un "centinela avanzado que espíe hasta los movimientos más insignificantes de los conquistadores". 54

Las numerosas riquezas con que contaba la región y los aportes que hacía a la renta nacional ameritaban que el Chocó fuera declarado Departamento. Una y otra vez, insistieron en el peso que las exportaciones de platino, oro, caucho, tagua, ipecuana y maderas tenían en la balanza comercial colombiana. "La exportación general que hace el Chocó gira alrededor de \$4.000.000, es decir, la décima parte de la exportación general de toda la República". Esa cifra, señalaban, colocaba "a esta comarca en situación mucho más ventajosa, que a muchos de los Departamentos del interior”. El gobierno colombiano, aseveraban, debía tener en cuenta que para 1918 el Chocó pagaba por derechos aduaneros la nada despreciable cifra de $\$ 1.000,000$. En otros términos, "si las rentas nacionales ascienden a \$18.000.000 el Chocó contribuye con la décima octava parte". 55

Las implicaciones políticas que suponía el paso de Intendencia Nacional a Departamento también fueron utilizadas para concitar el apoyo de los chocoanos. "Departamento es sinónimo de autonomía, es decir de vida propia e independiente, sostuvo Reinaldo Valencia. ${ }^{56}$ El nuevo estatus significaba, además, contar con nuevos espacios de representación política, entre ellas una Asamblea Departamental. A esta entidad política, "irían representaciones de todos los municipios a darnos ordenanzas que consulten las necesidades, las aspiraciones y los derechos de estos pueblos abandonados de todos los gobiernos". ${ }^{77}$

Dos de las voces de origen afrodescendiente que se vincularon a este debate inicial fueron la del concejal Daniel Mosquera Lozano y las del ya citado escritor Gregorio Sánchez. Mosquera Lozano, aparte de insistir en las riquezas del Chocó y en su privilegiada posición geográfica, argumentó que esta región era "parte importante del territorio nacional" y que sus habitantes se caracterizaban por un "probado patriotismo". ${ }^{58}$ Sánchez, a través del ABC, expresó que la declaratoria de Chocó como departamento era el antídoto definitivo contra las aspiraciones anexionistas de las élites caucanas. "No se ha perdido el sentido común en la tierra de Conto, para

\footnotetext{
54 “Reforma constitucional", $A B C$, Quibdó, 24 de agosto de 1918.

55 "El Departamento", $A B C$, Quibdó, 28 de agosto de 1918.

56 "El mismo tema", $A B C$, Quibdó, 30 de agosto de 1918.

57 "Sobre el yunque", $A B C$, Quibdó, 18 de septiembre de 1918.

58 "Proyecto", $A B C$, Quibdó, 24 de agosto de 1918.
} 
preferir la anexión obscura, triste, anuladora, a la autonomía definitiva que traerá la institución departamental", concluyó. ${ }^{59}$ De manera que, al igual que lo descrito por Sharika Crawford para el caso de la Intendencia de San Andrés, algunos habitantes negros del Chocó reclamaron la autonomía política de su territorio reafirmando su pertenencia y lealtad a Colombia. ${ }^{60}$

Pese a la voluntad de los congresistas y a la sistemática campaña realizada por el $\mathrm{ABC}$, la propuesta fue votada negativamente. Chocó seguía careciendo del número de habitantes exigidos por la ley para ser Departamento. Los esfuerzos para lograr tal propósito no se detuvieron, sin embargo. A las expresiones de carácter individual le siguieron acciones de tipo colectivo, expresadas en la creación de organizaciones multirraciales a través de las cuales sectores de origen afrodescendiente lucharon por la autonomía política, económica y territorial del Chocó. La creación de comités cívicos y ligas regionales, como el mencionado al inicio de este texto, fueron los esfuerzos más comunes. Organizaciones de esta naturaleza venían formándose en distintas regiones de Colombia. Una de esas regiones fue la costa Caribe, donde empresarios, políticos y profesionales de Cartagena, Barranquilla y Santa Marta crearon La Liga Costeña en 1919. Su conformación fue la respuesta de estos sectores a una serie de medidas centralistas que se implementaron durante el gobierno de Marco Fidel Suarez (19181921). ${ }^{61}$ Esta liga, en su primera asamblea en enero de 1919, envió un comunicado al intendente del Chocó para que invitara "al pueblo chocoano a ingresar en la Liga, como medio de favorecer el desarrollo de esa importante región, cuyos intereses son solidarios con los de este litoral y con los de la patria común". ${ }^{6}$

El ABC, tras publicar el citado comunicado, abrió una encuesta para conocer la opinión de los ciudadanos en torno a la propuesta de vincular al Chocó a la Liga costeña. Algunos apelando a los vínculos geográficos y comerciales existentes entre ambas costas, expresaron su simpatía con la citada propuesta. ${ }^{63}$ No dispongo de evidencias que indiquen que finalmente los chocoanos dieran ese paso. Lo cierto es que en la década del veinte los estudiantes que estaban cursando sus estudios fuera de Chocó crearon el Comité de Acción Chocoana, en 1923, y luego, en 1926, la ya mencionada Liga Pro-Chocó, en Bogotá y Medellín respectivamente. ${ }^{64}$

Algunos de los estudiantes negros tuvieron una figuración destacada en las citadas ligas. Este fue el caso de Diego Luis Córdoba, quien fundó y presidió la Liga Pro-Chocó. Esta liga, creada para lograr el progreso de la región y para "dar a

\footnotetext{
59 "La opinión chocoana", $A B C$, Quibdó, 3 de octubre de 1918.

${ }^{60}$ Sharika, Crawford, "Under the Colombian Flag': Nation-Building on San Andrés and Providence Islands, 1886-1930”, (Tesis doctoral), University of Pittsburgh, 2009.

${ }^{61}$ Una discusión sobre el surgimiento e impacto de la Liga Costeña puede verse en Posada Carbó (1985).

62 "La Liga costeña", $A B C$, Quibdó, 7 de enero de 1919.

63 "La encuesta", $A B C$, Quibdó, 28 de enero de 1919.

64 "La colonia chocoana residente en Bogotá organiza un comité de acción chocoana" y "El Comité Chocoano", $A B C, 13$ y 18 de diciembre de 1923; "Comité de acción chocoana", $A B C$, Quibdó, 1 de abril de 1924.
} 
conocer lo mucho que la Intendencia vale, su historia, su geografía, sus riquezas, sus hombres...", ${ }^{65}$ adelantó acciones que consideraban necesarias para lograr la erección de Chocó en Departamento. Los integrantes de esta organización, en primer lugar, se preocuparon por forjar en los habitantes de Chocó un sentido de identificación y pertenencia con su región. Esa suerte de sentido identitario empezaron a forjarlo a través de la publicación de libros que destacaran los procesos y personajes históricos más representativos del Chocó. También insistieron en que esta intendencia, al igual que otros departamentos del país, debía contar con un himno elaborado por los propios habitantes del Chocó. Solo de esta manera, decían los miembros de la liga, se podía avanzar en acciones que "nos harán estremecer de patriotismo y amor por nuestra patria chica". ${ }^{66}$

En ese esfuerzo por fortalecer la identidad regional, la Liga también se preocupó por vencer las rivalidades políticas existentes entre las provincias del Atrato y la de San Juan. Así como las élites caucanas y antioqueñas presionaban para acceder a las riquezas mineras de la última provincia, al interior de esta hubo voces que plantearon la posibilidad de anexarse a otro departamento. La élite de San Juan constantemente señalaba que por su peso económico merecía ser la capital de la intendencia, y no pocas veces reclamaba mayor representación en la burocracia local, usualmente acaparada por la élite de Quibdó. ${ }^{67}$

Superar estas rivalidades políticas, argumentaban los miembros de la Liga Pro-Chocó, era una condición sine qua non para avanzar en la materialización de las pretensiones de Chocó como región. "La Liga Pro-Chocó...acordó dirigirse a la prensa chocoana para suplicarle, trabaje en el sentido de sembrar entre los chocoanos un poco más de unión y espíritu público", decía una de las cartas enviada por los directivos de este centro cívico al director del ABC. Diego Luis Córdoba, Ernesto González, Emilio Dualiby y Vicente Barrios Ferrer, miembros de la Junta directiva de la Liga Pro-Chocó, insistían en que era necesario incentivar e inculcar ese espíritu de unión y servicio, pues "como usted bien sabe, señor director, son estos esenciales elementos para la realización de la obra que nos proponemos llevar a cabo". ${ }^{68}$ La Liga también centró sus esfuerzos en reclamar la presencia de chocoanos en los altos cargos de la administración pública. En 1926, por ejemplo, la Liga Pro-Chocó participó activamente en una campaña para que la principal autoridad de la intendencia fuera un hijo del Chocó.

El proceso de tropicalización que experimentaron los espacios de mayorías negras y mulatas, en el marco del impacto de las ideas del racismo científico en Colombia, había incidido en el nombramiento personas de este origen racial en cargos de representación política. Bajo el argumento de que Chocó carecía de

\footnotetext{
65 "La Juventud Antioqueña y el Chocó”, $A B C$, Quibdó, 8 de junio de 1926.

66 "El libro del Chocó", $A B C$, Quibdó, 19 de julio de 1926; "El Himno del Chocó”, $A B C$, Quibdó, 11 de octubre de 1926.

67 "Por última vez”, $A B C$, Quibdó, 13 de septiembre de 1918.

68 "La Liga Pro-Chocó y el director del ABC", $A B C$, Quibdó, 28 de septiembre de 1926.
} 
personas preparadas para ser designados como intendentes, el presidente nombraba a profesionales y políticos provenientes del Cauca, Antioquia o la misma Bogotá para desempeñar el cargo en mención. Entre 1910 y 1930, ninguno de los intendentes nombrados fue de origen afrodescendiente.

Los miembros de la Liga Pro-Chocó, ante este panorama, presionaron al presidente conservador Miguel Abadía Méndez para que aceptara una terna que estuviera integrada por chocoanos. Desde diversas municipalidades que hacían parte de la intendencia se enviaron comunicados que solicitaron el nombramiento de Jorge Valencia Lozano, miembro del partido conservador y hermano del director del ABC. Incluso, en Itsmina, principal centro urbano de la Provincia de San Juan, se creó el periódico Acción Chocoana con el propósito de "luchar por la tierra y por la candidatura del Dr. Jorge Valencia Lozano por el puesto del intendente del Chocó". ${ }^{69}$

La Liga Pro-Chocó, con Diego Luis Córdoba a la cabeza, declaró abiertamente su apoyo a Jorge Valencia Lozano. "Chocoanos, al lanzar candidatura suya Intendencia, obraron magníficamente", expresaron en una carta que le dirigieron directamente al futuro intendente. ${ }^{70}$ Frente a la posible designación de un intendente proveniente de la ciudad de Cali, la liga Pro-Chocó envió un extenso comunicado al presidente Miguel Abadía Méndez en el que, aparte de sugerir que el gobierno debía invertir en vías de comunicación y en la educación y salud de la población chocoana, insistieron en lo conveniente que era el nombramiento de Lozano Valencia como nuevo intendente. ${ }^{71}$

Los debates realizados por los miembros de la liga Pro-Chocó y distintos sectores políticos de las provincias chocoanas finalmente empezaron a dar sus frutos. En octubre de 1926, el presidente Abadía Méndez, ante la sugerencia de nombrar un intendente que proviniera de la región del Cauca, reconoció que no era posible, pues "los chocoanos se manifiestan opuestos al nombramiento de un intendente que no sea oriundo de la región". ${ }^{72}$ El 25 enero de 1927, luego de seis meses de intensas campañas de los chocoanos por contar con su propio intendente, el presidente Miguel Abadía Méndez anunció su decisión. Con el apoyo decidido de la Liga Pro-Chocó y las masas conservadoras y algunos sectores liberales, Valencia Lozano terminó siendo designado como nuevo intendente del Chocó. ${ }^{73}$

La designación de Valencia Lozano como intendente, sin embargo, dejaba sin resolver problemas centrales de representatividad política de los habitantes de del Chocó. Al no ser departamento, por seguir careciendo de los habitantes y las

\footnotetext{
69 “Acción Chocoana”, $A B C$, Quibdó, 21 de agosto de 1926.

70 "La Liga Pro-Chocó y la candidatura Valencia", $A B C$, Quibdó, 6 de julio de 1926.

71 "Una maciza exposición de los estudiantes chocoanos en Medellín al Doctor Miguel Abadía Méndez", $A B C, 19$ de julio de 1926 .

72 "El Doctor Abadía Méndez hace una vez más de que el intendente del Chocó no será del interior", $A B C$, Quibdó, 11 de octubre de 1926.

73 "el Dr. Valencia Lozano fue nombrado intendente", $A B C$, Quibdó, 25 de enero de 1927.
} 
rentas anuales requeridas por la ley, electoralmente seguía dependiendo de Antioquia, jurídicamente del Cauca y administrativamente de Bogotá. La dependencia electoral de Antioquia, sin embargo, empezó a jugar a favor de los líderes chocoanos una vez los liberales llegaron al poder en 1930. Mayoritariamente liberal, Chocó y sus dirigentes fueron visualizados por los liberales antioqueños y del país como un territorio y líderes claves para minar la tradicional hegemonía ejercida por el conservatismo en ese departamento. El primer movimiento del Directorio Liberal de Antioquia, con miras a asegurar el apoyo de las masas liberales chocoanas, fue incluir a Adán Arriaga Andrade como miembro suplente del citado directorio en $1930 .{ }^{74}$ Un año después, en la elección a representantes a la Cámara, inscribieron a Diego Luis Córdoba como candidato suplente, y en 1933 ocupó uno de los renglones principales como aspirante al mismo cuerpo legislativo. ${ }^{75}$ El Directorio Conservador de Antioquia, ante los movimientos del liberalismo, también incluyó en su listado de candidatos a políticos negros. En 1933, cuando Diego Luis Córdoba participó por vez primera como candidato principal a la Cámara de Representantes, el conservatismo lanzó al político negro Osías Lozano Quintana y a Eliseo Arango. En el marco de estas disputas por el dominio político territorial, Córdoba y Lozano Quintana fueron electos por vez primera como miembros del congreso. ${ }^{76}$

El poder local y regional adquirido por algunos de estos líderes negros y mulatos y su relevancia en la vida política nacional fue determinante en la lucha por la departamentalización del Chocó. Al igual que en las primeras décadas del siglo $\mathrm{XX}$, como lo han reconstruido trabajos previos, la intendencia seguía enfrentando un escenario adverso para ser declarada departamento. ${ }^{77}$ Las divisiones entre las provincias de San Juan y la del Atrato se habían agudizado. El Representante a la Cámara Sergio Abadía Arango, político liberal mulato, natural de la provincia de San Juan y hermano del poderoso comerciante y minero negro Antonio Asprilla Arango, presentó proyectos para que convirtieran la intendencia en dos comisarías. ${ }^{78}$ Habitantes de los territorios chocoanos que limitaban con Panamá, ante la poca presencia e inversión de las autoridades, nuevamente expresaron su intención de separarse de Colombia y anexarse al otrora territorio colombiano. ${ }^{79} \mathrm{Y}$, sobre todo, Chocó seguía sin contar con el número de habitantes y la renta anual exigidas por la ley.

Inquebrantables, sin embargo, continuaban las aspiraciones departamentales. Estudiantes y profesionales nuevamente utilizaron la prensa regional $(A B C)$ y nacional (El Heraldo de Antioquia y El Liberal de Bogotá) para reclamar la consecución de ese

\footnotetext{
74 "En el nuevo directorio liberal de Antioquia quedó el Chocó con un representante", $A B C$, Quibdó, 7 de marzo de 1930.

75 “El Directorio Liberal de Medellín lanzó la plancha de candidatos liberales”, $A B C$, Quibdó, 19 de abril de 1933.

76 “Como quedó confeccionado el renglón de candidatos conservadores del Chocó”, $A B C$, Quibdó, 25 de abril de 1933.

77 Juan, Hernández, "La chocoanidad en el siglo XX”, 50-51.

78 “El Departamento y las comisarías”, $A B C$, Quibdó, septiembre 9 de 1933.

79 "Los habitantes de Juradó en la región del Chocó quieren formar parte del territorio chocoano", $A B C$, Quibdó, 17 de febrero de 1934.
} 
propósito. ${ }^{80}$ Los comités pro-Chocó liderados por estudiantes, profesionales y obreros de origen afrodescendiente, que reclamaron mayor autonomía para la intendencia en la década del veinte, aparecieron en escena. ${ }^{81}$ Desde cada uno de estos espacios, como si se tratara de un inmodificable libreto, insistieron en que Chocó - por su posición estratégica, sus riquezas minerales, los aportes que hacía al fisco nacional, y ante una posible ocupación de su territorio por parte de Estados Unidos- debía ser departamento. ${ }^{82}$

Lo que sí había variado era el estatus de algunos de los protagonistas que venían escribiendo ese libreto desde las primeras décadas del siglo XX. Ya no se trataba -como en los años veinte- de estudiantes que reclamaban autonomía desde Bogotá, Cali o Medellín; ahora, de regreso a su territorio y moviéndose en los círculos de poder local, regional y nacional, eran líderes políticos dispuestos a interpretar el papel de abanderados de la causa departamental. ${ }^{83}$ Sus acciones se desarrollaron en dos frentes. A nivel interno, defendieron la unidad territorial del Chocó. En 1933, en el marco del proyecto de convertir la intendencia en dos comisarías presentado por Arango, el periodista y político negro Andrés Fernando Villa (firmaba bajo el seudónimo Aristo Velarde), en calidad de presidente del Concejo Municipal de Quibdó, solicitó a la Cámara de Representantes abstenerse de "considerar un proyecto que va contra los intereses nacionales, porque atenta contra la autonomía del Chocó. ${ }^{84}$ Un año después, Adán Arriaga Andrade, en su condición de intendente, creó la Provincia del Pacífico, integrada por los municipios de Juradó, Baudó y Nuquí, evitando que se materializaran las pretensiones anexionistas de algunos de los habitantes de esos territorios a Panamá. ${ }^{85}$

En el contexto nacional, apenas llegaron a la Cámara de Representantes, presentaron proyectos para que Chocó pudiera ser Departamento sin llenar los requisitos exigidos por la ley. ${ }^{86}$ Junto a estas propuestas iniciales, que fueron rechazadas, presentaron otras que fueron allanando el camino hacia la departamentalización. Lozano Quintana y Córdoba, en su primer período como congresistas, lideraron un proyecto que le permitió a la Intendencia del Chocó contar con un distrito judicial autónomo que dirimiera las causas civiles y penales. ${ }^{87}$ Diez años más tarde, congresistas chocoanos, entre ellos Diego Luis Córdoba y Adán Arriaga Andrade, consiguieron la aprobación de un acto legislativo a través del cual al Chocó se le permitió aspirar

\footnotetext{
80 “Antioquia y el Chocó”, El Heraldo de Antioquia, Medellín, 1 de agosto de 1935.

81 "Comité permanente de acción chocoana", $A B C$, Quibdó, 12 de diciembre de 1940.

82 "El aporte del Chocó al fisco nacional”, $A B C$, Quibdó, 4 de mayo de 1934, "Bloqueo en el Chocó", $E l$ Liberal, Bogotá, 29 de junio de 1944.

${ }^{83}$ Luis Fernando, González, (2003), Quibdó: Contexto histórico, desarrollo urbano y patrimonio arquitectónico (Medellín: Universidad Nacional de Colombia, 2003).

84 "El concejo municipal de Quibdó protestó ayer en forma vehemente contra el doctor Abadía Arango", $A B C$, Quibdó, 6 de septiembre de 1933.

85 "La nueva provincia del Pacífico”, ABC, Quibdó, 14 de septiembre de 1934.

86 "Los representantes Córdoba y Lozano proponen la erección de la Intendencia en Departamento", $A B C$, Quibdó, 9 de septiembre de 1933.

87 "Proyecto de ley", $A B C$, Quibdó, 24 de octubre de 1933.
} 
a la departamentalización sin tener el número de habitantes e ingresos requeridos. ${ }^{88}$ En 1947, haciendo uso de este decreto ejecutivo, estas mismas dos figuras lograron que el Congreso finalmente aprobara la declaratoria del Chocó como Departamento, resolviendo el tema de la representatividad política nacional para este territorio de la costa Pacífica, y, al hacerlo, abrieron el camino para que otros territorios nacionales se ilusionaran y reclamaran su conversión en departamentos. ${ }^{89}$

\section{Conclusión}

El estudio del rol que jugaron líderes de origen afrodescendiente en la consecución de mayores niveles de autonomía para el hoy Departamento del Chocó permite reconstruir dos procesos estrechamente interrelacionados. El primero tiene que ver con el intento de desconectar este espacio y sus habitantes de cualquier rastro de modernidad. Élites intelectuales y políticas del mundo andino, amparados en la composición racial del territorio chocoano, lo describieron como un espacio sin rastro de civilización y cultura. En el marco de la relación centro/periferia que ha caracterizado la interacción entre estas regiones y Bogotá, el inveterado manejo centralista del poder por parte de las élites colombianas, además, terminó marginándola políticamente.

El segundo proceso que revela la investigación sobre los sectores negros y mulatos del Chocó es que la marginalidad que se intentó imponer desde el mundo andino sobre el citado territorio y sus habitantes en el orden racial, político y económico nacional no se correspondió con el rol central que históricamente han jugado sus habitantes en cada una de esas esferas. Los debates y acciones que adelantaron líderes negros y mulatos de la Intendencia del Chocó por defender y alcanzar mayores niveles de autonomía administrativa y política también muestran que, pese a ser marginados desde el centro del país, no fueron sectores que se sintieran marginales. Lejos de ser los bárbaros e incivilizados descritos por las élites del mundo andino y sus pares regionales, se vieron como ciudadanos que a través de su participación en debates públicos podían contribuir a definir el destino de su región. Y en efecto, gracias a sus múltiples esfuerzos, no solo lograron que los intendentes que iban a dirigir los destinaos del Chocó fueran oriundo de ese territorio, sino que, finalmente, lograron que el Chocó adquiriera el estatus de departamento en 1947.

\section{Bibliografía}

\section{Fuentes primarias}

\section{Prensa}

ABC (Quibdó) 1914, 1918, 1919, 1923, 1924, 1926, 1927, 1930, 1933, 1934, 1935, 1940, 1943.

\footnotetext{
88 “Aprobada la reforma constitucional para le erección del Chocó en Departamento en el senado", $A B C$, Quibdó, 3 de diciembre de 1943.

89 “Hombres del Chocó”, Semana, Bogotá, 1947.
} 
El Gráfico (Quibdó) 1927.

El Liberal (Bogotá) 1943, 1944.

Gaceta de la Intendencia (Quibdó) 1912, 1920, 1926.

La Aurora (Quibdó) 1928.

Semana (Bogotá) 1947.

\section{Fuentes secundarias}

\section{Libros}

Appelbaum, Nancy. Mapping the Country of Regions. The Chorographic Commission of Nineteenth-Century Colombia, Chapell Hill: University of North Carolina Press, 2016.

Arias Vanegas, Julio. Nación y diferencia en el siglo XIX colombiano. Orden nacional, racialismo y taxonomías poblacionales. Bogotá, Uniandes/Ceso, 2015.

González, Luis Fernando. Quibdó: Contexto histórico, desarrollo urbano y patrimonio arquitectónico. Medellín: Universidad Nacional de Colombia, 2003.

Helg, Aline. Liberty and Equality in Caribbean Colombia 1770-1835, Chapel Hill: University of North Carolina Press, 2004.

Jiménez, Miguel. Nuestras razas decaen. Algunos signos de degeneración colectiva en Colombia y en los países similares. El deber actual de la ciencia _Bogotá: Imprenta y Litografía de Juan Casis, 1920.

Leal, Claudia. Landscape of Freedom. Building a Postemancipation Society in the Rainforest of the Western Colombia, Tuscon: University of Arizona Press, 2018.

López de Mesa, Luis. Escrutinio sociológico de la historia colombiana, Bogotá: Academia colombiana de historia. Segunda edición, 1956.

Múnera, Alfonso. Fronteras imaginadas. La construcción de las razas y la geografía en el siglo XIX colombiano, Bogotá: Planeta, 2005.

Múnera, Alfonso. El fracaso de la nación. Región, raza y clase en el Caribe colombiano, 1717-1810, Bogotá: editorial Planeta, 1998.

Merizalde del Carmen, Bernardo. Estudio de la costa colombiana del Pacífico, Bogotá: Imprenta del estado mayor general, 1921. 
Marginados, pero no marginales. Negros, mulatos y sus disputas por la autonomía en Chocó,...

Pisano, Pietro. Liderazgo político 'negro' en Colombia, 1943-1964, Bogotá: Universidad Nacional de Colombia, Facultad de Ciencias Humanas, 2012.

Roldan, Mary. A sangre y fuego. La violencia en Antioquia, Colombia 1946-1953, Bogotá, ICANH/ Fundación para la promoción de la Ciencia y la tecnología, 2003.

Serje, Margarita. El revés de la nación. Territorios salvajes y tierras de nadie, Bogotá: Uniandes-CESO, 2005.

Steiner, Claudia. Imaginación y poder: el encuentro del interior con la costa en el Urabá, 1860-1900, Medellín, Universidad de Antioquia, 2003.

Wade, Peter. Music, Race and Nation: Música Tropical in Colombia, Chicago: University of Chicago Press, 2000.

Wade, Peter. Blackness and Race Mixture. The Dynamics of Racial Identity in Colombia, Baltimore: John Hopkins University Press, 1993.

\section{Artículos de revista}

Alarcon Meneses, Luis y Conde calderon, Jorge. "Social Representations of National Territory and Citizenships in Nineteenth-Century History and Geography Textbooks of the Colombian Caribbean Region, Pedagógica Histórica: International Journal of the History of Education, (2007) Vol. XLIII, No 5, Carfax and Publishing limited.

Appelbaum, Nancy. "Muddied Waters: Race, Region, and Local History in Colombia, Durham: Duke University Press", The American Historical Review, (2003) Vol. 109, $\mathrm{N}^{\circ}$ 4: 23-38.

Crawford, Sharika. "Panama Fever: Colombian Fears of Secession on San Andrés and Providencia Islands, 1903-1913", The Global South 2, Interoceanic Diasporas and The Panama Canal's Centennial, (2012) Vol. 6, N²: 15-38.

Flórez Bolívar, Francisco Javier. "Representaciones del Caribe colombiano en el marco de los debates sobre la degeneración de las razas: geografía, raza y nación a comienzos del siglo XX”, en Historia y Espacio, (2008) Vol. 4 Núm. 31: 15-41.

Helg, Aline. "Los intelectuales frente a la cuestión racial en el decenio de 1920: Colombia, entre México y Argentina", en Estudios Sociales, (1989) No. 4, Medellín, FAES: 37-53.

Lasso, Marixa. "Nationalism and Immigrant Labor in a Tropical Enclave: the West Indians of Colon City, 1850-1936”, Citizenship Studies, (2013) V.17, ํ⒌

Leal, Bernardo. "Matar a los blancos bueno es, luego Chocó acabará: cimarronaje de esclavos jamaiquinos en el Chocó", (1998) Fronteras 2:2. 
Leal, Claudia. "La compañía minera Chocó-Pacífico y el auge del platino en Colombia, 1897-1930", Historia Critica, (2009), Vol. 39: 150-164.

McGraw, Jason. "Purificar la nación: eugenesia, higiene y renovación moral-racial de la periferia del caribe colombiano, 1900-1930", Estudios Sociales, (2004) № 27 : $62-75$.

Meisel Roca, Adolfo. “Por qué se disipó el dinamismo industrial de Barranquilla?”, Lecturas de economía, (1987) Vol 23: 57-84.

Restrepo, Eduardo. "Imágenes del "negro" y nociones de raza en Colombia a principios del siglo XX”, Estudios Sociales, (2007), Vol. 27.

Rhenals Doria, Ana Milena. "Tejiendo la red: circuitos comerciales, inmigrantes siriolibaneses y empresarios nacionales en el Caribe colombiano y el Atrato (18801930)", Historia y Espacio, (2012 Vol. 37: 189-212.

Sharp, William. "La rentabilidad de la esclavitud en el Chocó", Hispanic American Historical Review, (1975), Vol.55, ํ⒊

Villegas Vélez, Álvaro. "Raza y nación en el pensamiento de Luís López de Mesa: Colombia, 1920-1940”, Estudios Políticos, (2005) Vol. 26: 209-232.

\section{Tesis, ponencias y otros}

Crawford, Sharika. "Under the Colombian Flag': Nation-Building on San Andrés and Providence Islands, 1886-1930”, Ph.D. diss., University of Pittsburgh, 2009.

González, Luis Fernando. "Jorge Isaacs y la ruta del Caribe por el chocó. Memorias, comercio, esclavitud y modernidad”, Memorias de Primer Simposio Internacional Jorge Isaacs el creador en todas sus facetas. Cali: Universidad del Valle. p. 337347, 2007.

Hernández, Juan. "La chocoanidad en el siglo XX: Representaciones sobre el Chocó en el proceso de departamentalización (1913-1944) y en los movimientos cívicos de 1954 y 1987', Tesis de pregrado, Universidad Javeriana, 2010.

Leal, Claudia (2004), Black Forests. The Pacific Lowlands of Colombia, 1850-1930. University of California. Ph. D. Dissertation.

Posada Carbó, Eduardo (1985), “La liga costeña, una expresión de poder regional”, Boletín Cultural y Bibliográfico, 22:3.

Rhenals Doria, Ana Milena (2013), Del ideal europeo a la realidad árabe. Inmigrantes sirio-libaneses en el circuito comercial entre Cartagena, el Sinú y el Atrato (Colombia), 1880-1930, Universidad Pablo de Olavide (España), Tesis doctoral. 